of a moderate gale from the north-westward, and much thunder and lightning occurred. Unsettled weather continued from the 2 Ist to the 24 th, and from this day a storm area can be clearly traced travelling to the westward. The cyclone reached its greatest violence on June 2 and 3 , when the barometer is reported as reading 27.86 inches in close proximity to the centre of the disturbance. A hurricane occurred at Obokh during the evening of the $3 \mathrm{rd}$, and it was reported that all the houses but one had been blown down, and trees had been uprooted. The position of the storm area is not only marked throughout its passage across the Arabian Sea by the cyclonic circulation of the winds, but also by the rain area which accompanied the disturbance; the rate of progress of the storm from May 24 to June 3 was rather less than seven miles an hour.

The second cyclone which is shown by the charts appears to have originated not far distant from Ceylon at the commencement of June, and on the 4th a strong south-westerly gale was blowing on the equator in the longitude of $76^{\circ} \mathrm{E}$. This storm can be traced for the next ten days, during which time it passed to the northward and westward towards the entrance of the Persian Gulf. The weather was very disturbed over nearly the whole of the Arabian Sea from the 9th to the 13 th, and the area of the storm was much larger than in the case of the Aden cyclone, and gales were experienced from the coast of Africa to that of India, extending over a distance of about I 500 miles. The synchronous weather charts for the last few days of the discussion, after the cyclonic disturbances had passed away, show that the south-west monsoon had extended over the whole of the Arabian Sea, whereas in the middle of May it was limited chiefly to the western side.

Each daily chart contains the observations from several ships in the Red Sea, where the wind direction and other elements of the weather are very instructive. The southerly march of the northerly or north-westerly wind, which throughout the whole period prevails over the northern portion of the Sea, and the gradual backing down of the southerly winds in the southern portion of the Sea are well shown. The northerly wind in the northern portion of the Red Sea often attains the force of a gale, but there is no instance in the charts of the southerly winds attaining gale force. The air temperature is generally higher in the Red Sea than over the more open water in the Arabian Sea, the reading of the thermometer commonly reaching $90^{\circ}$, and on June 14 the temperature at 10 o'clock in the morning was $102^{\circ}$ over the open sea, nearly abreast of Musawwá. The charts show many other points of interest, among these the flow of the current under the influence of disturbed weather as well as when the sea is comparatively quiet, and doubtless the volume will throw some additional light on the winds and weather in this part of the world, where at present the meteorological changes are not too well understood.

\section{ON VAN DER WAALS'S ISOTHERMAL EQUATION.}

I N reply to Prof. Tait's criticism (NATURE, December 31, I 891, p. 199) of my paper (December I7, p. I52) I wish to say that I certainly do not consider Van der Waals's $b$ as an absolute constant. Perhaps it may be interesting to show how the limits of its variability can be determined.

Leaving aside the question of the attractive forces, which probably has been sufficiently elucidated in the course of this discussion in the columns of NATURE, and considering gases as aggregations of elastic spheres, then in the formula-

$$
p_{1}\left(v-x b_{1}\right)=\frac{1}{3} \Sigma m u^{2}
$$

$x$ can be proved to be equal to 4 for large volumes and small pressures.

No. I I 60, VOL. 45]
Again, in the case of extremely large pressures, when the volume is nearly reduced to the smallest possible dimensions, it is easy to see that a formula-

$$
p_{1}\left(v-\mu b_{1}\right)=\frac{1}{3} \lambda . \Sigma m u^{2} . . . .(2)
$$

must hold good, where $\mu b_{1}=3 \sqrt{2} / \pi, b_{1}=\mathrm{r} 35 \ldots b_{1}$ represents the space in which the spherical molecules can be inclosed when they are motionless, and $\lambda$ is a certain numerical coefficient whose determination might present some interest, and perhaps is not beyond the scope of mathematical analysis. (For one-dimensional motion $\lambda=\mathrm{r}$.) Be this as it may, putting (2) in the form-

$$
t_{1}\left[v-\left(\mathrm{x}+\frac{\lambda-\mathrm{r}}{\lambda} \cdot \frac{v-\mu b_{1}}{\mu b_{1}}\right) \cdot \mu b_{1}\right]=\frac{1}{3} \Sigma m u^{2}, \ldots \text {. (3) }
$$

it is clear that in this case $x$ approaches the value $\mu=\mathbf{I} \cdot 35$.

Now surely, for intermediate volumes and pressures, $x b_{1}$ cannot be considered as a constant; still, along the large range of these pressures, the correction required must be called relatively slight, and the more so as it is beyond doubt that a considerable part of the change from 4 to I.35 takes place near those extreme pressures where, according to (3), $x$ may be very variable. Whether at the critical volume this coefficient has undergone already a practically important change from its original value, 4 , seems to me a question which cannot easily be answered by purely theoretical considerations.

In my opinion, in all cases except in that of large volumes the formula (I) is preferable to a formula

$$
p_{1} v=\frac{1}{3}\left(\mathrm{I}+\frac{4 b_{1}}{v}+\frac{\sigma b_{1}^{2}}{v^{2}}\right) \cdot \Sigma m u^{2}, .
$$

even if the numerical value of $\sigma$ could be exactly calculated; therefore the question at issue does not simply turn on the introduction or rejection of terms of the order $\beta^{2} / v^{2}$, and it was looking at the matter from this point of view that in my paper I once called a formula of the form (I) the true one as distinguished from a formula of the form (4), and not from any formula given by Prof. Tait. Certainly, none of the isothermal equations given by different authors can be named true in the sense of representing with absolute exactness the conduct of real gases; and of course, when more constants are introduced in these equations than are contained in that of Van der Waals, a better approximation to the conduct of these gases may be reached.

In conclusion, I beg to add a few words about Prof. Tait's third remark. It seems to me that he has no right to identify the process of putting arbitrarily $\gamma=\beta$ with that of calculating the correction indicated by Prof. Lorentz.

Amsterdam, January 6.

D. I. KORTEWEG.

\section{NOTES.}

Several scientific meetings have been postponed in consequence of the death of the Duke of Clarence. Prof. W. E. Ayrton, F.R.S., was to have delivered his inaugural address, as President of the Institution of Electrical Engineers, on January 14. It will be delivered at a meeting of the Institution on January 28. The annual general meeting of the Royal Meteorological Society, fixed for the 20 th, will be held on the 27 th, when the President, Mr. Baldwin Latham, will deliver an address on "Evaporation and Condensation." The annual meeting of the Entomological Society is also adjourned from the 20 th to the 27 th.

THE forty-fifth annual general meeting of the Institution of Mechanical Engineers will be held on Thursday and Friday evenings, February 4 and 5 , at 25 Great George Street, West- 